\title{
Coronary heart disease and elderly people
}

\author{
No mass treatment of risk factors yet
}

Because the risks of coronary heart disease and the prevalence of risk factors increase with age possible benefits from preventive programmes are much greater in elderly people. The significance of risk factors for coronary heart disease in elderly people, however, remains uncertain. Despite more than three in four deaths from coronary heart disease occurring in people over 65 , few observational studies and even fewer clinical trials have focused on this age group. With more old people and more opportunity to modify risk factors this information gap becomes more important.

Extrapolating from studies in middle aged people may be wrong. The relative risks of coronary heart disease associated with the standard risk factors weaken with increasing age, perhaps because of selective survival and competing risks, and elderly people may be more susceptible to the side effects of interventions.

In elderly people high blood pressure is common and is associated with an increased risk of coronary heart disease. About half the population of the United States aged 65-74 is hypertensive (defined either as taking antihypertensive drugs or having a systolic blood pressure $\geqslant 160 \mathrm{~mm} \mathrm{Hg}$ or a diastolic

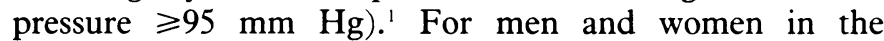
Framingham cohort who reached 65 without coronary heart disease the risk of subsequent coronary heart disease gradually increased with increasing systolic blood pressure. ${ }^{2}$ Other studies do not confirm this,${ }^{3+}$ and the limited evidence from controlled trials must be interpreted cautiously. ${ }^{5}$

Blood cholesterol concentration increases with age in both cross sectional and cohort studies. Mean blood cholesterol concentrations run parallel in men and women until their $60 \mathrm{~s}$, when concentrations in men, but not women, plateau. The serum total cholesterol concentration is commonly high in elderly people; in the Framingham cohort $35 \%$ of men and $60 \%$ of women over 65 had cholesterol concentrations greater than $6.0 \mathrm{mmol} / \mathrm{l}^{2}$

Whether serum total cholesterol concentration is a risk factor for coronary heart disease in elderly people is even less clear than for hypertension. Early reports from the Framingham study suggested that serum cholesterol concentration did not predict coronary heart disease after $65 .{ }^{6}$ More recent analyses from the study, based on longer follow up and using more sophisticated analytical methods, have found a relation. ${ }^{2}$ Associations have been found between blood total cholesterol concentration and coronary heart disease in some ${ }^{47}$ but not all other studies. ${ }^{3}$ Only limited data exist on the association of high density lipoprotein cholesterol concen- trations and coronary heart disease in elderly people ${ }^{8}$ Without properly conducted trials of lipid lowering treatment in this age group, screening for high blood cholesterol concentrations and subsequently treating elderly people cannot be justified. ${ }^{9}$

In this issue ( $p$ 89) prospective data from the Whitehall study of male civil servants are used to explore the significance of plasma cholesterol concentrations measured at age 40-69 for coronary heart disease over the subsequent 18 years. ${ }^{10} \mathrm{~A}$ single plasma cholesterol measurement predicted death from coronary heart disease, although the strength of the association declined with age. In men who died aged 60-69 plasma cholesterol concentration measured at least five years earlier was also positively related to total mortality. These data, which require confirmation, suggest that lowering cholesterol concentrations in middle age might reduce the risk of coronary heart disease in old age.

The increased relative risk of coronary heart disease caused by cigarette smoking decreases in older age groups, " perhaps because of the selective loss of smokers due to premature death. Nevertheless, in a cohort of people aged 65-74 in Chicago current smokers had a risk of dying from coronary heart disease $50 \%$ higher than that of non-smokers, with the excess risk declining within one to five years after smoking stopped. ${ }^{3}$ Similar results have been reported recently in a prospective study of older men and women from three communities in the United States, ${ }^{12}$ although other studies have found no such association with smoking. ${ }^{2+}$ No studies of passive smoking and coronary heart disease have specifically studied elderly people.

Limited data suggest that exercise in elderly people may be associated with the same apparent benefits as in young people. ${ }^{13}$ Habitual alcohol consumption is associated with reduced risks of coronary heart disease in middle aged men and women, and in many studies this association does not seem to be explained by the misclassification of former drinkers. ${ }^{1+}$ Although the apparent protective effect of alcohol on coronary heart disease might be expected to be independent of age, insufficient epidemiological data exist on this topic. ${ }^{15}$

From a population perspective even small increases in relative risks in elderly people will be associated with a large burden of disease because the rates of disease are so high. Further studies are required to assess the significance of risk factors in elderly people and whether reducing these risk factors will have the same beneficial effect as in younger age groups. Intervention studies are urgently required, particularly of non-pharmacological interventions, with both 
mortality and morbidity as end points. Until these data are available mass treatment of risk factors in elderly people should be avoided.

ROBERT BEAGLEHOLE

Professor of Community Health,

School of Medicine,

University of Auckland,

New Zealand

1 Drizd T, Dannenberg AL, Engel A. Blood pressure levels in persons 18-74 years of age in 1976-1980 and trends in blood pressure from 1960-1980 in the United States. Washington, DC: US Government Printing Office, 1986. (US Department of Health and Human Services publication No (PHS) 861684 , Series 11 , No 224 .

2 Harris T, Cook EF, Kannel WB, Goldman L. Proportional hazards analysis of risk factors for coronary heart disease in individuals aged 65 or older. $\mathcal{F}$ Am Geriatr Soc 1988;36:1023-8.

Jajich CL, Ostfeld AM, Freeman DH. Smoking and coronary heart disease mortality in the elderly. JAMA $1984 ; 252: 2831-4$

4 Barrett-Connor E, Suarez L, Khaw K-T, Crequi MH, Wingard DL. Ischemic heart disease risk factors after age 50. 7 Chronic Dis 1984;37:903-8
Amery A, Brixko P, Clement D, et al. Mortality and morbidity results from the European working party on high blood pressure in the elderly trial. Lancet 1985; i:1349-54.

6 Gordon T, Castelli WP, Hjortland MC, Kannel WB, Dawber TR. Predicting coronary heart disease in middle-aged and older persons: the Framingham study. JAMA 1977;238:497-9.

Benfante R, Reed D. Is elevated serum cholesterol level a risk factor for coronary heart disease in the elderly? FAMA 1990;263:393-6.

8 Castelli WP, Wilson PWF, Levy D, Anderson K. Cardiovascular risk factors in the elderly. Am $\mathcal{f}$ Cardiol 1989;63:12-9H.

9 Garber AM, Littenberg B, Sox HC, et al. Costs and effectiveness of cholesterol screening in the elderly. Washington, DC: Office of Technology Assessment, US Government Printing Office, 1989.

10 Shipley MJ, Pocock SJ, Marmot MG. Does plasma cholesterol concentration predict mortality from coronary heart disease in elderly people? 18 year follow up in Whitehall study. $B M \mathcal{J}$ 1991:303:000-00.

11 Doll R, Peto R. Mortality in relation to smoking: 20 years' observation of male British doctors. $B M \mathcal{B}$ 1976; ;i: $1525-36$.

12 LaCroix AZ, Lang J, Scherr P, et al. Smoking and mortality among older men and women in three communities. N Engl f Med 1991;324:1619-25.

13 Donahue RP, Abbott RD, Reed DM, Yano K. Physical activity and coronary heart disease in middle-aged and elderly men: the Honolulu heart program. Am $\mathcal{F}$ Public Health 1988;78:683-5.

14 Criqui $\mathrm{MH}$. The reduction of coronary heart disease with light to moderate alcohol consumption: effect or artifact. Br f Addict 1990;85:854-7.

15 Colditz GA, Branch LG, Lipnick RJ, et al. Moderate alcohol and decreased cardiovascular mortality in an elderly cohort. Am Heart $\gamma$ 1985;109:886-9.

\section{New deal for old hearts}

\section{Age alone should be no barrier to treatment}

With the insatiable demand for health care health economists and politicians continue to remind doctors that they must help choose how best to use the limited resources. Because of the pressure on existing services many doctors have been reluctant to refer older patients for specialist investigation and treatment of heart disease. A joint working group on cardiological intervention in elderly patients argues for a more enlightened approach, based on risk-benefit analysis for each patient. Its report emphasises that well judged intervention in elderly people may be very worth while. ${ }^{1}$

In general the morbidity and mortality of disease increase with age, so the potential value of intervention in elderly people is substantial. Use of thrombolytic agents in acute myocardial infarction is a good example. Studies suggest that the relative benefit and risk of thrombolytic treatment are similar in all age groups; the absolute benefit (the total number of lives saved), however, seems greatest in elderly patients because they have a much higher case fatality. ${ }^{2}$ Soper has calculated that each quality adjusted life year ${ }^{3}$ saved by thrombolytic treatment costs half as much in patients aged over 65 as it does in patients aged under $55 .{ }^{+}$No justification exists, therefore, for the common practice of imposing age limits for thrombolytic treatment or admission to a coronary care unit.

The place of cardiac surgery and percutaneous transluminal angioplasty in elderly people is less clear. Cardiac surgery, particularly aortic valve replacement for aortic stenosis, is undoubtedly of great value in patients over $70 .^{5}$ Similarly, angioplasty in octogenarians has a high rate of angiographic and clinical success. ${ }^{6}$ On the other hand, these procedures are expensive and the incidence of complications increases with age. The excess risk may, however, be overstated because the threshold for intervention, and therefore the severity of the underlying disease, also tends to increase with age.

By contrast, cardiac pacing for complete heart block is well established as a highly cost effective and appropriate treatment in the elderly. Sadly, British patients seem to be missing out. The rate of implantation of pacemakers in Britain is still less than half that reported in the United States, France, Germany, and many other European countries. ${ }^{7}$ Most of the shortfall has been attributed to centralisation of services and the lamentable fact that in the United Kingdom seven million people still have no immediate access to specialist cardiological services. ${ }^{89}$ Indeed, providing a local pacing service and appointing a local cardiologist both produce a dramatic and appropriate increase in the rate of implantation of pacemakers. ${ }^{1011}$

Underprovision is not peculiar to cardiac pacing. In 1988 there were 89 percutaneous transluminal angioplasties performed per million population in the United Kingdom-less than one tenth the rate in the US and less than a third of that in most European countries. ${ }^{12}$ This is hardly surprising, given that Britain has fewer than six cardiologists per million people compared with 45 per million in Europe as a whole and the recommended 60 per million in the US. ${ }^{8}$

The demand for cardiac surgery and specialist cardiological services for elderly people will increase as the numbers grow, their expectations (and those of their families and doctors) increase, and innovation continues. Given current NHS funding the gap between what is medically possible and what is affordable is likely to grow. We can at least seek to ensure that everyone has access to specialist cardiological services and try to allocate resources to what will do most good. Perhaps then age alone will no longer bar patients from effective treatment.

N A BOON

Consultant Cardiologist,

Royal Infirmary of Edinburgh,

Edinburgh EH3 9YW

1 Royal College of Physicians. Report of joint working group on cardiological intervention in elderly patients. London: RCP, 1991.

2 patients. London. RCP, 1 R intravenous streptokinase, oral aspirin, both or neither among 17187 cases of suspected acute myocardial infarction: ISIS-2. Lancet 1988;ii:349-60.

3. Williams A Economics of coronary artery bypass grafting. BM7 1985;291:326-9.

4 Soper J. Thrombolytic therapy in the early treatment of acute myocardial infarction: economic appraisal of treatment. In: Clinical resource and audit group conference. Royal College of Physician and Surgeons of Glasgow (in press).

5 Elder AT, Cameron EWJ. Cardiac surgery in the elderly can produce substantial benefits at a price of a moderately increased risk. BMF 1989;299:140-

6 Jeroudi MO, Kleiman NS, Minor ST, et al. Percutaneous transluminal coronary angioplasty in octogenarians. Ann Intern Med 1990;113:423-8.

7 Feruglio GA, Richards AF, Steinbach K, Feldman S, Parsonnet V. Cardac pacing in the world: survey of the state of art in 1986 . VIIIth world symposium on cardiac pacing and electrophysiology. Pace 1987; 10:623-786.

8 Rickards AF. Where's the block? BMF 1984;288:737-8.

9 Chamberlain D, Bailey L, Sowton E, Ballantyne D, Boyle DMcC, Oliver M. Staffing in cardiology in the United Kingdom 1988. Fifth biennial survey. Br Heart f 1989;62:482-7.

10 Godden DJ, MacCulloch MS, Sandhu PS, Kerr F. Correcting a block?: successful experience of a small British pacing centre. Br Heart f 1987:58:495-8.

11 Jacyna MR, Main G, Hanslip J, Pringle TH, Mcneill GP. The influence of cardiac staffing resources on permanent cardiac pacemaker implantation rates. Scott Med f 1988;33:261-3.

12 Hubner PJB. Cardiac interventional procedures in the United Kingdom during 1988. Br Heart $f$ 1990;64:36-7. 